\title{
Estudo das Funções Afins, Quadráticas e Equações Polinomiais com o auxílio do software Winplot no Ensino Médio
}

Silvio Márcio Costa de Jesus

Maria Deusa Ferreira da Silva

\begin{abstract}
Resumo
Neste artigo apresentamos um recorte da dissertação de mestrado realizada junto ao mestrado Profissional em Matemática em Rede Nacional PROFMAT- Pólo UESB, em Vitória da Conquista, em que relatamos a pesquisa do primeiro dos autores fazendo uso das novas tecnologias, no caso o Winplot, em suas atividades docentes, ao tempo que traz à tona relatos e discussões sobre as dificuldades que os professores de matemática ainda encontram em introduzir em suas atividades de ensino o uso desses recursos. Nesse sentido, buscamos identificar os motivos pelos quais professores de matemática do Ensino Médio não utilizam em sua docência os recursos computacionais, além de evidenciar, na própria prática, que esse uso é possível, relatando momentos da experiência realizada, com alunos das 1a e 3a séries do Ensino Médio, do Colégio Modelo Luis Eduardo Magalhães, Rede Pública Estadual, Itapetinga -Ba. As atividades em sala aula foram desenvolvidas com uso do Winplot e envolveu os conteúdos funções afim e quadráticas, para alunos da primeira série, e, funções polinomiais para alunos da terceira série. Neste artigo ainda trazemos algumas discussões teóricas sobreo uso das TIC e uma pequena parte dos resultados da pesquisa. Finalizando, apresentamos algumas das conclusões do trabalho, o qual aponta para importância do uso das TIC no ensino de matemática e reforça a necessidade de melhor formar os professores para utilizá-las.
\end{abstract}

Palavras-chave: TIC. Ensino de matemática. Formação de professores.

\section{Abstract}

This article we present a cut of the dissertation of the dissertation carried out by the Professional Masters in Mathematics in National Network -PROFMAT, in UESB, Vitória da Conquista, in which we report in which we report the research of first authors making use of new Technologies if the Winplot in her teaching activities, to the time it brings up to reports and discussions on the difficulties that teachers of mathematics still encounter in introducing into their teaching activities using these resources. In this sense, we seek to identify the reasons why mathematics teachers of high school do not use in their teaching the computational resources, besides showing in practice itself, that use is possible, reporting moments of experiment performed with students of the 10 and 30 high school class, College Model Luis Eduardo Magalhães, Itapetinga, Bahia. The activities in the classroom were developed with the use of the Winplot and involved the contents functions of first and second degree, for the students for the 1 o high school class and polynomial functions for the students of the 30 high school class. In this article still we bring some theoretical discussions about use of the TIC and a small part of the results of research. Finally, we present some 
conclusions of the work, which indicates the importance of the use of this TIC in teaching of the mathematics and reinforces the need to better training of the teachers to use them.

Keywords: TIC, Teaching of mathematics. Teacher training.

\section{Introdução: justificativas e motivações para a realização da pesquisa}

As discussões e implicações sobre o uso das Novas Tecnologias da Informação e da Comunicação (TIC), nos diversos setores da sociedade e, em especial na Educação, particularmente no ensino de matemática, já há muito nos instigava e despertava interesse. Todavia se acentuou nas discussões trazidas pela disciplina Recursos Computacionais no Ensino de Matemática, do mestrado Profissional em Matemática ${ }^{1}$, PROFMAT, uma vez que nos demos conta do avanço destas nos vários setores da sociedade, dos inúmeros softwares disponíveis para o ensino de matemática, e, por outro lado, percebemos que os professores de matemática ainda tem muita resistência em utilizá-las em suas aulas.

Já tínhamos, até certo ponto, a compreensão de que os recursos tecnológicos, como os softwares matemáticos, podem contribuir significativamente para melhoria do ensino da Matemática e potencializar a aprendizagem dos alunos. Contudo, precisávamos questionar para entender, sobretudo, nos espaços onde atuamos: Como as TIC influenciam o ensino de matemática atualmente? Quais as implicações educacionais decorrentes da inserção dos recursos tecnológicos no ensino da Matemática? O uso de softwares matemáticos pode auxiliar no ensino e aprendizagem da matemática? Quais as maiores dificuldades enfrentadas pelo professor de matemática para utilização desses recursos tecnológicos como ferramentas didáticas em suas práticas pedagógicas?

Assim, no transcorrer das discussões, na mencionada disciplina foi possivel tratar dessas questões com mais ímpeto nos instigando a conduzir uma pesquisa onde pudéssemos investigar como seria a experiência de utilizar, em nossas aulas, tais recursos e, ainda, saber/compreender o porquê dos professores de matemática ainda não utilizarem em suas aulas ou utilizá-las timidamente. Disso se configurou a pergunta diretriz da pesquisa que ora trazemos neste artigo, tal seja: É viável fazer uso dos recursos do Winplot em nossa prática de ensino de matemática nos estudos das funções afins, quadráticas e equações polinomiais? Com essa pergunta nos inserimos na tarefa de modificar a própria prática e vivenciar a experiência de fazer uso dos recursos tecnológicos em nossas aulas, usando o mencionado software. Isso nos levou a traçar objetivos, dentre os quais destacamos, identificar as potencialidades do software Winplot para o ensino da matemática no Ensino Médio; identificar as principais dificuldades encontradas pelos

${ }^{1}$ Integra o conjunto de disciplinas eletivas do PROFMAT

R. B. E. C. T., vol 8, núm. 1, jan-abr.2015 ISSN - 1982-873X

DOI: Em andamento. 
professores de matemática que justifiquem a utilização ou não dos recursos computacionais; analisar o interesse dos alunos do ensino médio ao utilizarem o computador como recurso didático no ensino da matemática.

\title{
Sobre os recursos computacionais: a formação de professores e o uso no ensino de matemática
}

Vivemos na denominada sociedade tecnológica. Isso se deve aos constantes avanços das tecnologias (as TIC) que mudaram nossa forma de viver em sociedade. Baseados nisso, constantemente, nos colocamos diante da seguinte pergunta: Seria possível viver nesse mundo sem a presença das modernas tecnologias para realizar as nossas tarefas do cotidiano? Em resposta a tal pergunta pode-se concluir que seria muito complicado, pois vivemos em uma sociedade tecnológica e globalizada, onde os seus mais diversos setores dependem em maior ou menor grau dessas tecnologias. A ausência delas tornaria difícil ou mesmo impossível realizar tarefas simples do dia-a-dia. E como fica a educação nesse contexto?

Segundo Suzuki e Rampazzo (2009), Moran, Masetto e Behrens (2008), as tecnologias alteraram sensivelmente todos os setores da sociedade e a educação não ficou isenta, já que é um setor fundamental nesse cenário de mudanças. As TIC podem trazer muitos avanços à prática pedagógica do professor, sendo sua utilização nos cenários educacionais uma exigência. Isso requer maiores desafios para os profissionais envolvidos, em especial os professores, os quais são os responsáveis diretos por essa incorporação. É importante também destacar a posição de Tornaghi (2006) quando afirma que:

\begin{abstract}
"A chegada das tecnologias de informação e comunicação (TIC) na escola evidencia desafios e problemas relacionados aos espaços e a os tempos que $o$ uso das tecnologias novas e convencionais provocam nas práticas que ocorrem no cotidiano da escola. Para entendê-los e superá-los é fundamental reconhecer as potencialidades das tecnologias disponíveis e a realidade em que a escola se encontra inserida, identificando as características do trabalho pedagógico que nela se realizam, de seu corpo docente e discente, de sua comunidade interna e externa. (TORNAGHI, 2006, p. 61)"
\end{abstract}

Assim, a inserção das novas tecnologias no ambiente escolar vem alterando este substancialmente e abrindo para novas possibilidades, o que requer, dos diretamente envolvidos, capacidade de superar os muitos obstáculos. Conquanto, devemos, por outo lado, ver nas TIC uma oportunidade para repensar e, possivelmente, resolver muitos dos problemas e dificuldades inerentes ao meio, em especial, em relação à aprendizagem. No entanto, percebemos que a relevância de tais recursos vai muito além de seu uso por si só. É necessário criar condições e 
situações que efetivamente promovam a melhora na qualidade do ensino e da aprendizagem, onde quer que esse uso se faça. Nesse sentido Kenski (2007), diz que:

"Não há dúvidas de que as novas tecnologias de comunicação e informação trouxeram mudanças consideráveis e positivas para a educação. Vídeos, programas educativos na televisão e no computador, sites educacionais, softwares diferenciados transformam a realidade da aula tradicional, dinamizam o espaço de ensino-aprendizagem, onde, anteriormente, predominavam a lousa, o giz, o livro e a voz do professor. Para que as TICS possam trazer alterações no processo educativo, no entanto, elas precisam ser compreendidas e incorporadas pedagogicamente. Isso significa que é preciso respeitar as especificidades do ensino e da própria tecnologia para poder garantir que o seu uso, realmente, faça diferença. Não basta usar a televisão ou o computador, é preciso saber usar de forma pedagogicamente correta a tecnologia escolhida. (KENSKI, 2007, p. 46)."

Desse modo, um variado número de recursos tecnológicos está à disposição da educação, ficando a cargo do professor avaliar e selecionar o recurso que melhor se adeque às suas necessidades e possibilidades. Tajra (2008) afirma que para a integração da tecnologia ao contexto escolar, é preciso: verificar os pontos de vista dos professores em relação aos impactos dessas tecnologias na educação; levar os alunos a perceberem como tais impactos alteram sua vida cotidiana; integrar os recursos tecnológicos de forma significativa com as necessidades educacionais dos alunos. Nessas considerações podemos acrescentar ainda que fazer uso das novas tecnologias pode ser uma forma de trazer o aluno para o nosso lado, uma vez que estão muito mais abertos a esse uso.

Ainda, é importante que a escola esteja inserida no contexto tecnológico, uma vez que todos os setores da sociedade já estão utilizando esses recursos para realizarem suas tarefas. Porém, mesmo diante da situação atual, ainda acontece de muitos ambientes educacionais estarem à margem das novas tecnologias. Isso os coloca na contramão da realidade na qual está inserida. Na contramão também do universo dos jovens. Talvez a dificuldade da escola em absorver tudo isso esteja na velocidade com que as mudanças ocorrem. O que nos leva a concordar com Moran et. al. (2008) quando afirmam que "passamos muito rapidamente do livro para a televisão e vídeo e destes para o computador e a internet, sem aprender e explorar todas as possibilidades de cada meio". (MORAN, 2008, p. 32).

Outro aspecto relevante em relação ao uso das TIC diz respeito à formação dos professores para utilizá-las. Do professor espera-se a capacidade de saber utilizá-las de modo que venham fazer parte de sua ação docente, não apenas aprendendo sobre elas, mas incorporandoas em suas atividades de ensino como uma ferramenta para aprendizagem dos alunos. Isso requer conhecimento e capacidade de planejar e criar ambientes de aprendizagem que venham 
favorecer a construção do conhecimento dos seus alunos. Corroborando com esse fato, Suzuki e Rampazzo (2009) afirmam,

"Diante desta nova situação, o professor terá necessidade de atualização constante, tanto em sua disciplina específica, quanto nas metodologias de ensino e as novas tecnologias. Nesse sentido, destacamos a importância da formação continuada. Além disso, espera-se do professor do século XXI que ele seja capaz de desenvolver os conteúdos não só de forma individual, mas também coletiva, e que saiba manejar os instrumentos especificos dos novos tempos. (SUZUKI e RAMPAZZO, 2009, p. 40)“

Desse modo, é importante, ou melhor, é imprescindível que o professor esteja capacitado em relação a essa nova realidade social, e por que não dizer educacional, por conta do uso das TIC, de tal maneira que nossa integrar a tecnologia à sua proposta pedagógica. Os professores que priorizam melhorar as suas competências e metodologias de ensino precisam estar abertos para absorver o uso dos recursos computacionais e estarem em constante estado de aprendizagem e mudança. No entanto, Sancho et. al. (2006) apontam alguns problemas que dificultam ou inviabilizam a incorporação das TIC por parte dos professores no processo ensino e aprendizagem:

- "Especificações e níveis dos currículos atuais;

- Restrições da própria administração;

- Esquemas organizativos do ensino (aulas de 45-50 minutos);

- A organização do espaço - acesso aos computadores, número de estudantes por sala de aula;

- Os sistemas de formação permanente dos professores que impedem a mudança educativa;

- O conteúdo disciplinar dos currículos que dificultam as propostas transdisciplinares e a aprendizagem baseada em problemas;

- As restrições na organização de espaço e tempo;

- A falta de motivação dos professores para introduzir novos métodos;

- A pouca autonomia de professores e alunos. (SANCHO, 2006, p. 26)"

Além desses fatores, Roulkousky (2011) aponta a formação dos professores como um fator preponderante na utilização das novas tecnologias. Segundo o autor mesmo diante do grande apelo da sociedade e a crescente oferta de computadores nas escolas, o número de professores que utilizam a informática na rede pública ou privada de ensino ainda é incipiente. Um dos maiores motivos é o descompasso entre a introdução da tecnologia na educação e a 
formação dos professores. Portanto, a formação do professor precisa contemplar o uso das novas tecnologias permitindo que ele seja capaz de incorporá-las em sua prática docente. Além disso, de acordo com Suzuki e Rampazzo (2009), o professor precisa ter novas posturas, assumir a mediação no ensino, adotar a prática interdisciplinar, ensinar a pensar e ensinar a aprender, reconhecer os impactos das novas tecnologias na escola. Diante do exposto, podemos afirmar que o uso das TIC, terá lugar, de forma adequada, no ambiente educacional, quando existir um projeto de para utilizá-la e uma postura adequada dos profissionais envolvidos, em especial os professores.

Em se tratando de recursos tecnológicos, merece destaque os especialmente voltados para o ensino da matemática, são muitos. Contudo, talvez seja uma das áreas em que a inserção desses recursos tenha sido menor. As novas tecnologias não conseguiram ainda causar impacto no ensino e aprendizagem da disciplina, embora seja uma recomendação proposta nos PCN conforme segue:

"O impacto da tecnologia na vida de cada indivíduo vai exigir competências que vão além do simples lidar com as máquinas. Esse impacto da tecnologia, cujo instrumento mais relevante é hoje o computador, exigirá do ensino de Matemática um redirecionamento sob uma perspectiva curricular que favoreça o desenvolvimento de habilidades e procedimentos com os quais o indivíduo possa se reconhecer e se orientar nesse mundo do conhecimento em constante movimento. (PCN, 2000, p. 41)."

Sem dúvida, as TIC não são o único caminho para se obter bons resultados no ensino e aprendizagem da matemática. Porém, é de se esperar que seja um caminho natural o uso dos recursos tecnológicos, em especial o computador, por tudo que já apresentamos anteriormente. Espera-se que os alunos familiarizados com esses recursos possam demonstrar mais interesse e, possivelmente, melhores desempenhos fazendo uso de tais ferramentas voltadas ao ensino da matemática (GUIMARÃES, 2010). Ainda para Guimarães (2010, p. 71):

"O computador é outro recurso que também pode ser um grande aliado nas aulas de matemática. Entretanto, infelizmente, ele tem conseguido pouco espaço nas escolas. Muitas vezes, os professores, por não possuírem intimidade com essa tecnologia, acabam deixando de lado esse importante e motivador recurso."

Portanto, reafirmamos que o papel do professor é relevante, ele não pode mais permanecer como mero retransmissor de conhecimento. Espera-se dele, nesse novo cenário, capacidade para inovar e estabelecer uma nova relação com os alunos, uma vez que os alunos fazem parte de uma geração mais afeita às tecnologias e mostram-se mais abertos e envolvidos com o seu uso. Assim, cabe ao professor a tarefa de inteirar-se dessas ferramentas, sendo 
mediador, motivador e organizador das situações de ensino e aprendizagem. E para isso são inúmeras as possibilidades que oferecem os recursos computacionais, dentre elas o uso de softwares e a internet. No nosso caso optamos pelo uso do Winplot por se tratar de um software gratuito e de fácil manuseio.

\section{A metodologia de pesquisa}

A pesquisa visou mostrar a viabilidade do uso dos recursos tecnológicos para o ensino da matemática no Ensino Médio, mas especificamente usando o software Winplot no estudo das funções afim, quadrática e equações polinomiais, bem como apresentar as propostas de atividades desses conteúdos tendo como um dos recursos didáticos o software acima citado. A pesquisa foi feita em ambiente escolar e com a participação de alguns professores e alunos, portanto, a opção foi por uma pesquisa de abordagem qualitativa. Conforme Cruz (2010):

"Os estudos qualitativos podem descrever a complexidade de determinado problema e a interação de certas variáveis, compreender e classificar os processos dinâmicos vividos por grupos sociais, contribuir no processo de mudança de dado grupo e possibilitar, em maior nível de profundidade, o entendimento das particularidades do comportamento dos indivíduos. (CRUZ, 2010, p. 112)."

Ainda sobre a pesquisa qualitativa, afirma Moreira (2011):

"Pesquisa qualitativa é um termo que tem sido usado alternativamente para designar várias abordagens à pesquisa em ensino, tais como pesquisa etnográfica, participativa observacional, estudo de caso, fenomenológica construtivista, interpretativa, antológica cognitiva. Cada uma dessas abordagens forma um todo coerente, englobando suposições internamente consistentes sobre natureza humana, sociedade, objeto de estudo $e$ metodologia, porém compartilham muitas semelhanças e por questões de simplicidade são comumente chamadas de pesquisa qualitativa. (MOREIRA, 2011, p. 46,47)."

Sendo assim, esse trabalho se caracterizou tal qual uma pesquisa qualitativa centrada em dois eixos: professores de matemática e alunos do Ensino Médio. Junto aos professores de matemática aplicamos um questionário para verificar como vem se dando a utilização de recursos tecnológicos em suas práticas pedagógicas, bem como, identificar as possíveis dificuldades que justifiquem o não uso desses recursos. Enquanto que junto aos alunos do Ensino Médio (1a e $3^{\underline{a}}$ séries) desenvolvemos atividades de ensino, como parte da carga horária prevista para a 
disciplina matemática nas respectivas séries. Na realização dessas atividades aproveitamos para avaliar o envolvimento e o desempenho dos alunos, sujeitos da pesquisa, ao utilizarem os recursos tecnológicos, bem como analisar suas potencialidades e os resultados com o uso do software Winplot.

\section{Sujeitos da pesquisa}

Então, como exposto, no trabalho de dissertação foram sujeitos da pesquisa professores de matemática e duas turmas de matemática do Ensino Médio, em que o primeiro dos autores era o professor e também pesquisador. A opção de também analisar o perfil e a percepção dos professores em relação aos recursos tecnológicos como ferramenta para a prática pedagógica no ensino de matemática se deve pela seguinte justificativa - os recursos computacionais já estão à disposição da educação há algum tempo e o mercado oferece um gama de softwares, em especial os de uso livre. Assim, seria de se esperar que fosse uma prática corriqueira dos professores o uso dessas ferramentas em sua prática pedagógica. No entanto, apesar de todos esses fatores e da crescente necessidade de integrar as tecnologias à educação, muitos alunos sequer tem a oportunidade de vivenciar na escola a utilização dessas tecnologias. Daí a importância de conhecer a opinião dos professores sobre o uso ou não dessas tecnologias, em especial na cidade onde a pesquisa foi realizada.

Desta forma, participaram da pesquisa 18 professores de matemática, das redes pública e/ou privada do Município de Itapetinga-BA, que atuam em pelo menos uma turma do Ensino Médio. Ainda, 31 alunos da 1a série e 39 alunos da 3a série do Ensino Médio do Colégio Modelo Luis Eduardo Magalhães, do mesmo município.

\section{Instrumentos de coleta de dados}

Para a coleta de dados os instrumentos adotados foram três questionários: um aplicado aos professores e dois aos alunos, um em cada série. Além disso, foram realizadas as atividades desenvolvidas com o uso do software Winplot nas referidas turmas do Ensino Médio. O uso do questionário como instrumento de pesquisa vem sendo bastante utilizado, uma vez que apresenta como vantagens a rapidez nas respostas e, em alguns casos, maior liberdade para quem responde, por conta das respostas não serem necessariamente identificadas. É o que afirma Fachin (2006).

"O fato de o questionário ser preenchido pelo próprio pesquisado, sem a presença do pesquisador, garante o anonimato muitas vezes necessário. $O$ anonimato contribui para que o pesquisado se sinta mais seguro $e$ 
consequentemente, favorece respostas mais verdadeiras. (FACHIN, 2006, $p$. 162)."

Assim, o questionário aplicado aos professores foi respondido sem a presença do pesquisador que os contatou e convidou-os a participarem da pesquisa. Após a explicação dos objetivos, foi marcada uma data para recolhimento dos mesmos. Essa etapa ocorreu entre os meses de outubro e novembro do ano de 2012. O questionário aplicado aos professores foi organizado com 20 questões, sendo 15 objetivas (de múltipla escolha) e 5 abertas (discursivas). Esse questionário visou obter informação sobre a prática pedagógica desses professores e os possíveis usos de recursos tecnológicos aliados à essa prática.

Já no caso dos alunos, os questionários foram aplicados após a realização das atividades em que os mesmos fizeram uso do software Winplot. Para os alunos da 1a série, foram propostas duas atividades: uma para o conteúdo Função Afim e outra para Função Quadrática. Aos alunos da 3a série, apenas uma atividade sobre o conteúdo Equações Polinomiais. Em ambos os casos, esses conteúdos já haviam sido ministrados na forma de aulas expositiva.

Então, em uma das aulas foi apresentado o software e convidamos os alunos a participarem da pesquisa. Assim, nesta mesma aula, com o auxílio do datashow, lhes apresentamos o software, mostrando alguns de seus recursos. Foi um momento de sensibilização e preparação para a aplicação das atividades, realizadas, posteriormente, no laboratório de informática da escola. Desse modo, pudemos realizar as atividades planejadas em duas horas/aulas, na turma de 3 a série, e no caso da 1a série, foram realizadas duas atividades, cada uma delas com a duração de duas horas/aula. Para facilitar o desenvolvimento dessas atividades foi elaborado um pequeno tutorial de orientação sobre como utilizar o software e distribuir aos alunos antes da realização da atividade. Isso facilitou o desenvolvimento das atividades, uma vez que o tutorial orientou no uso dos comandos do software bem como direcionou o aluno para a realização da atividade proposta.

Após a realização de cada uma dessas atividades, nas respectivas turmas, foi aplicado o questionário com o objetivo de detectar como esses alunos perceberam a utilização do computador bem como concebiam essas atividades, agora sendo feitas com o uso do software Winplot. Ainda foi possível analisar a opinião deles com relação ao ensino da matemática fazendo uso de recursos computacionais.

\section{Sobre a análise dos dados}

Como já informado, a pesquisa ocorreu em momentos distintos. Num primeiro momento foram coletados os questionários aplicados aos professores. As respostas dadas ao questionário possibilitaram obter dados a respeito da formação, titulação desses professores, tempo serviço, jornada de trabalho, dados sobre a prática pedagógica, do conhecimento e possível utilização de 
softwares, do uso do computador como ferramenta pedagógica para o ensino da matemática, e ainda, motivos que justifiquem a utilização ou não de tais recursos. Num segundo momento os alunos, em suas respectivas turmas e aulas, realizaram atividades elaboradas com base nos conteúdos: Funções Afins e Funções Quadráticas (na 1ạ série) e Equações Polinomiais (na 3a série). Essas atividades tiveram como objetivos aplicar os conhecimentos sobre os conteúdos acima citados e utilizar o software Winplot como recurso didático.

Assim, de posse desses dados resumidos em forma de gráficos, procedemos a uma analise e discussão comparando com o que trata a literatura sobre o uso dos recursos computacionais, além de colocar nossas próprias impressões sobre o coletado e observado nos diferentes momentos.

\section{As Atividades desenvolvidas em sala de aula \\ Atividade 1 - Trabalhando com a Função Afim}

Essa atividade foi divida em três tarefas. A partir do tutorial o aluno foi orientado sobre como usar determinadas ferramentas do software e realizar cada atividade proposta. Os tópicos abordados nessa atividade foram: construção do gráfico, determinação dos pontos com os eixos coordenados e ponto de interseção entre dois gráficos.

\section{TAREFA (01)}

Utilizando o Winplot, visualize o gráfico das seguintes funçốes e responda a cada pergunta sobre o mesmo:

1) $f(x)=2 x+6$

O gráfico toca o eixo $x$ ? Em que valor de $x$ ?

O gráfico toca o eixo $y$ ? Em que valor de $y$ ?
2) $f(x)=-5 x$

O gráfico toca o eixo $x$ ? Em que valor de $x$ ?

O gráfico toca o eixo y? Em que valor de y?

4) $f(x)=0,4 x+2$

O gráfico toca o eixo $x$ ? Em que valor de $x$ ?

O gráfico toca o eixo $y$ ? Em que valor de $y$ ?

DOI: Em andamento. 


\section{TAREFA (02)}

Utilizando o Winplot, obtenha o gráfico das funçỗes $f(x)=3 x+6$ e $f(x)=-0,5 x-5$. Responda:

1) Os gráficos têm ponto em comum?

2) Se sim, qual é a coordenada desse ponto de interseçẫo?

\section{TAREFA (03)}

Um estacionamento oferece duas opçốes de preço para seus clientes:

\section{A: R\$ 5,00 FIXO MAUS R\$ 0,50 POR HORA}

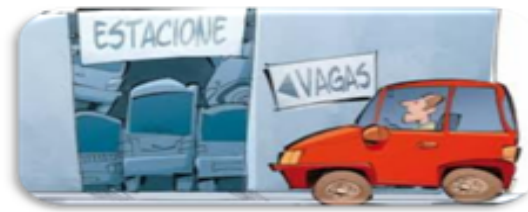

1) Determine as funçỗes que permitem calcular o preço pago y em funçã̃o do tempo $x$, das horas que o carro ficar no estacionamento.
A:
B:

2) Usando o winplot visualize o gráfico dessas funçổes.

3) Existe algum momento em que essas duas opçốes de pagamento vẫo gerar o mesmo preço?
( ) $\operatorname{sim}$
( ) กล๊̃o

\section{Atividade 2 - Trabalhando com a Função Quadrática}

Essa atividade também foi composta de três tarefas e, assim, como na atividade anterior, foi acompanhada do tutorial direcionando os alunos para realização de cada uma delas. Os tópicos abordados nessa atividade foram: obtenção de gráficos de funções quadráticas, pontos de interseção com os eixos coordenados e pontos extremos da função.

\section{TAREFA (01)}

Utilizando o Winplot, visualize o gráfico de cada uma das seguintes funçốes e responda as perguntas correspondentes:

1) $f(x)=x^{2}-2 x-3$

O gráfico toca o eixo $x$ ? Em quantos lugares?

O gráfico toca o eixo $y$ ? Em que valor de $y$ ?

Qual(is) o(s) valor(es) de $x$ nos pontos em que o gráfico toca o eixo $\times$ ?

3) $f(x)=-4 x^{2}+4 x-1$

O gráfico toca o eixo $x$ ? Em quantos lugares?

O gráfico toca o eixo $y$ ? Em que valor de $y$ ?

Qual(is) o(s) valor(es) de $x$ nos pontos em que o gráfico toca o eixo $x$ ?
2) $f(x)=-x^{2}+4 x$

O gráfico toca o eixo $x$ ? Em quantos lugares?

O gráfico toca o eixo $y$ ? Em que valor de $y$ ?

Qual(is) o(s) valor(es) de $x$ nos pontos em que o gráfico toca o eixo $x$ ?

4) $f(x)=2 x^{2}-\frac{5}{3} x+3$

O gráfico toca o eixo $x$ ? Em quantos lugares?

O gráfico toca o eixo $y$ ? Em que valor de $y$ ? Qual(is) o(s) valor(es) de $x$ nos pontos em que o gráfico toca o eixo $x$ ? 


\section{TAREFA (02)}

o vértice da parábola tem coordenada $V\left(x_{v}, y_{v}\right)$, tendo o $y_{v}$ como valor mínimo ou máximo, a depender da concavidade da parábola. Usando o Winplot obtenha o gráfico de cada funçấo, marque e detemine as coordenadas do seu vértice e identifique-o como mínimo ou máximo:

\begin{tabular}{l|l|l} 
1) $f(x)=x^{2}-5 x+2$ & $2) f(x)=\frac{1}{2} x^{2}+2 x$ & $3) f(x)=-x^{2}+\frac{3}{4} x-1$ \\
$x_{V}=$ & $x_{V}=$ & $x_{V}=$ \\
$y_{V}=$ & $y_{V}=$ & $y_{V}=$ \\
Vértice: & Vértice: & Vértice: \\
Mínimo ou máximo? & Mínimo ou máximo? & Mínimo ou máximo?
\end{tabular}

\section{TAREFA (03)}

Em uma partida de futebol, ao ser chutada por um jogador, a bola descreveu, até tocar o solo, uma trajetória definida pela sentença $y=\frac{5}{3} x-\frac{1}{27} x^{2}$, em que $y$ corresponde à altura da bola em relaçẫo ao solo após ter percorrido horizontalmente uma distância $x$



Observando o esquema e considerando as medidas de x e y em metros, pergunta-se:

1) A trajetória da bola descreve uma figura de que tipo?

2) Após o chute, que distância essa bola percorreu até tocar o solo pela 1 a vez?

3) Qual foi a altura máxima que a bola atingiu?

\section{Atividade 3 - Trabalhando com Equações Polinomiais}

Também essa atividade foi dividida em três tarefas. Com ela objetivamos explorar o conteúdo Equações Polinomiais. Esperávamos ainda consolidar melhor o que foi exposto em sala de aula, uma vez que os alunos, geralmente, o consideram difícil apresentando dificuldades na sua aprendizagem. Vale ressaltar também que esse conteúdo ao ser trabalhado no ensino médio não é comum explorar construções de gráficos. Assim, com o uso dos recursos computacionais isso se tornou possível, sendo um diferencial em relação à aula tradicional. Desse modo, utilizando o software foi possível ampliar a percepção e a compreensão que os alunos tiveram sobre o referido conteúdo. Desse modo, na realização dessa atividade foi possível explorar, além do gráfico da função, suas raízes reais, complexas, relação entre coeficientes e as raízes, os pontos extremos do gráfico. Então, a seguir apresentaremos o detalhamento das atividades. 


\section{TAREFA (01)}

Utilizando o Winplot, obtenha o gráfico dos polinômios seguintes e responda:

A) $P(x)=x^{3}+2 x^{2}-5 x-6$

- Quantas raizes possui $P(x)$ ? Quantas delas sẫo reais?

- Quais sã̃o essas raizes?

- Como se escreve $P(x)$ na forma fatorada?

B) $f(x)=2 x^{5}+6 x^{2}+4 x+2$

- Quantas raizes possui $f(x)$ ? Quantas delas sẫo reais?

- Algumas delas é um número inteiro? Estime um valor para essa raiz.

C) $A(x)=x^{4}-x^{3}-3 x^{2}+3 x$

- Quantas sã̃o as raízes de $\mathrm{A}(\mathrm{x})$ ?

- Todas elas sẫo reais? Por quê?

- O gráfico de $A(x)$ passa pela origem. Por quê?

\section{TAREFA (02)}

- Qual é o valor da raiz real do polinômio $f(x)=2 x^{5}+6 x^{2}+4 x+2$ da tarefa 01 ?

A) Esse valor está próximo da estimativa que você fez anteriormente?

- Insira no Winplot os valores dos coeficientes da equação $3 x^{5}-9 x^{4}+x^{3}+10 x^{2}-x-2,2=0$ e a partir do gráfico marque os pontos que são as raízes e dê seus valores numéricos.

Teorema: Se a soma dos coeficientes de uma equação algébrica é igual a zero, então o número 1 é raiz dessa equação.

- Elabore uma equação cuja soma dos coeficientes seja zero, completando os espaços na equação seguinte:

$$
x^{4}+\ldots x^{3}-\ldots x^{2}-\ldots+\ldots=0
$$

A) Use o dispositivo de Briot-Ruffini e comprove que 1 realmente é raiz dessa equação, encontrando resto zero.



B) Usando o Winplot, visualize o gráfico da equação que você elaborou e verifique se o seu gráfico tocou o eixo x no número 1 . 


\section{TAREFA (03)}

- Seja a equação $x^{4}-x^{3}-3 x^{2}+3 x-\frac{8}{5}=0$ e seu gráfico abaixo. Então:

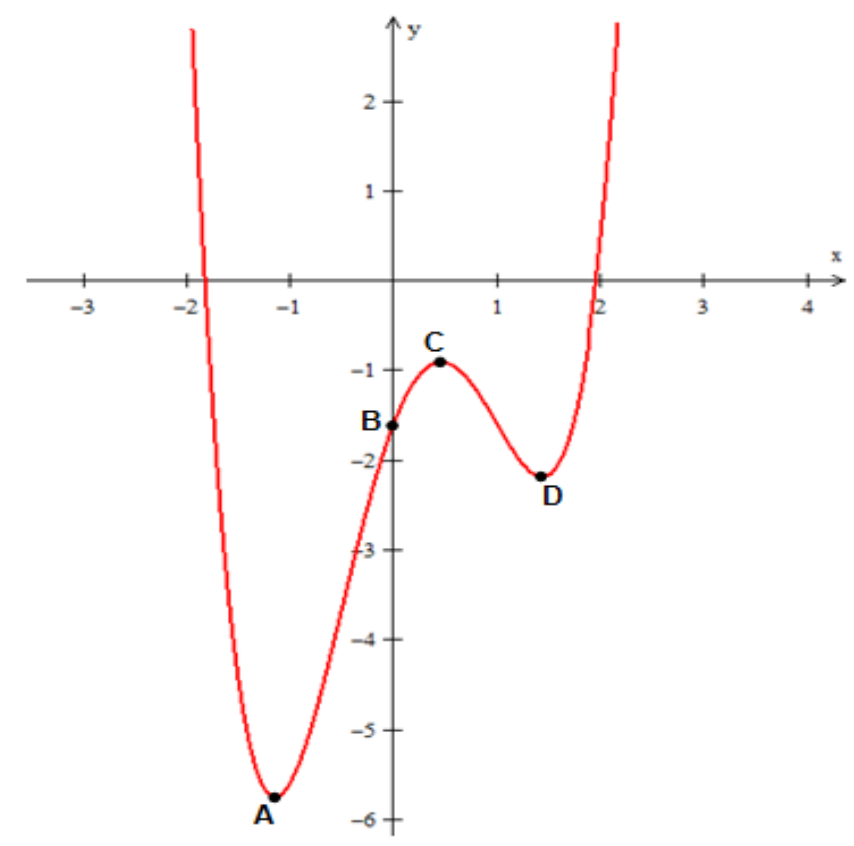

Qual é o valor de B?

Com o auxílio do Winplot analise o gráfico da equação acima e verifique se ficou idêntico ao da figura

- Dada a equação $-x^{4}+3 x^{3}-2 x-1=0$, usando o Winplot obtenha o seu gráfico, marque os extremos, determine cada coordenada e identifique-os como mínimos ou máximos, locais ou absolutos

\section{Discussão dos resultados}

\section{Acerca do Questionário Aplicado aos professores}

Sobre o questionário aplicado aos 18 professores as duas primeiras questões versaram sobre a formação acadêmica e a titulação dos professores. A questão 3 tratou sobre ser licenciado ou não em matemática, e a questão 4, sobre os cursos de pós-graduação dos mesmos. Os gráficos abaixo representam os resultados, a seguir, tratam dessas questões:

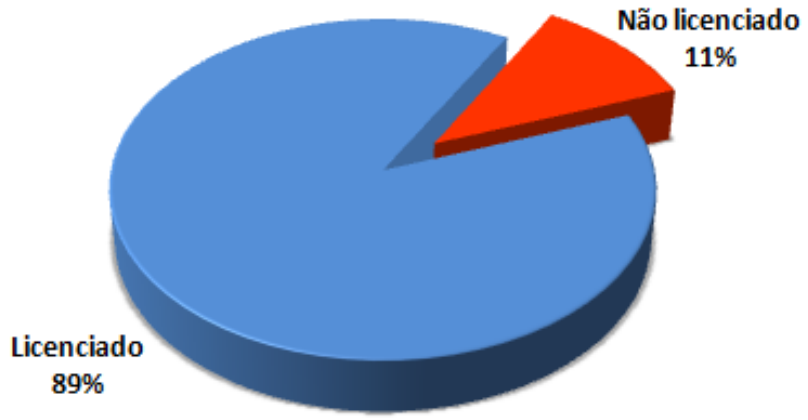

Gráfico 01 - Formaçäo dos professores



Gráfico 02 - Titulação em nivel de pós-graduação

DOI: Em andamento. 
Assim, esses dados mostram que a maioria tem formação específica para ensinar matemática com um percentual também alto com curso de especialização. Isso nos leva a considerar que os participantes estão preparados, pelo menos teoricamente, para ensinar na educação básica.

Nas questões seguintes foi perceptível que em se tratando da quantidade de instituições em que lecionam e da carga horária de trabalho semanal, verificou-se uma realidade comum entre muitos professores, ou seja, possuírem uma jornada de trabalho exaustiva, tendo uma carga horária semanal com muitas horas-aulas. Verificou-se que $44 \%$ dos professores têm entre 31 e 45 horas-aula por semana e $17 \%$ deles têm mais de 45 horas-aulas semanais.

Ainda, com base nas respostas dadas, 39\% desses professores trabalham em duas ou mais escolas, motivo pelo qual, segundo os mesmos, dificulta o planejamento das aulas e, acreditamos, a utilização de metodologias diversificadas, inclusive o uso das novas tecnologias. Desse modo, por atuarem em mais de uma escola, faz com que não crie um vínculo com um único ambiente de ensino. Esse fator também pode se constituir numa dificuldade para a realização de um trabalho pensado de forma coletiva entre os professores, sejam eles de áreas afins ou diferentes.

De acordo com o exposto, o gráfico a seguir ilustra as respostas dadas.

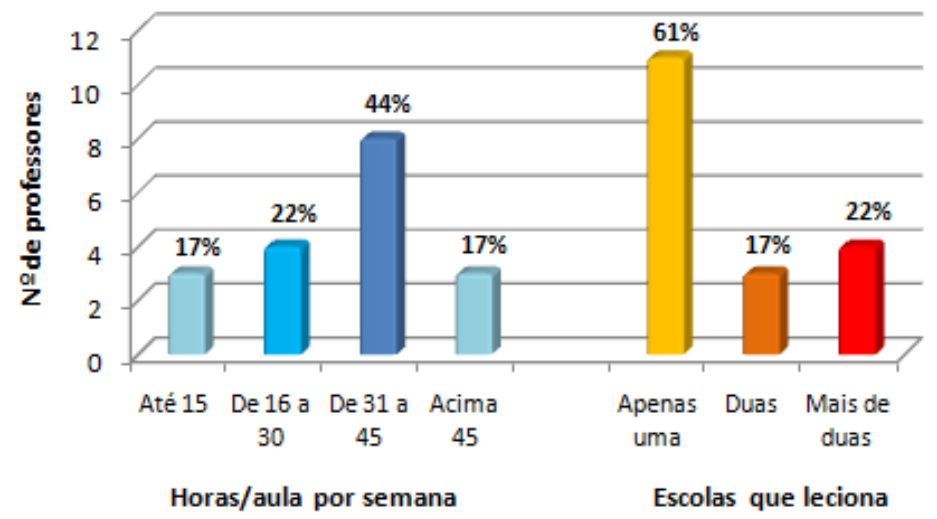

Gráfico 03 - Carga horária semanal e locais de trabalho

Algumas das questões buscaram averiguar a opinião dos professores sobre o uso dos recursos computacionais e suas implicações no ensino de matemática. Ao investigar sobre a existência ou não do laboratório de informática nas escolas em que os professores lecionam, constatamos que apenas duas das escolas envolvidas na pesquisa não possuem laboratório de informática, observamos então que o problema não está na falta dos equipamentos e sim por outros fatores, como: falta de coordenador para o laboratório, falta de tempo para elaborar aulas nesse ambiente, computadores com defeito, dentre outros. 
Ao serem questionados sobre o conhecimento de softwares matemáticos, os professores demonstraram conhecer vários deles, sendo o Winplot e o Geogebra os mais populares de acordo com o gráfico a seguir.

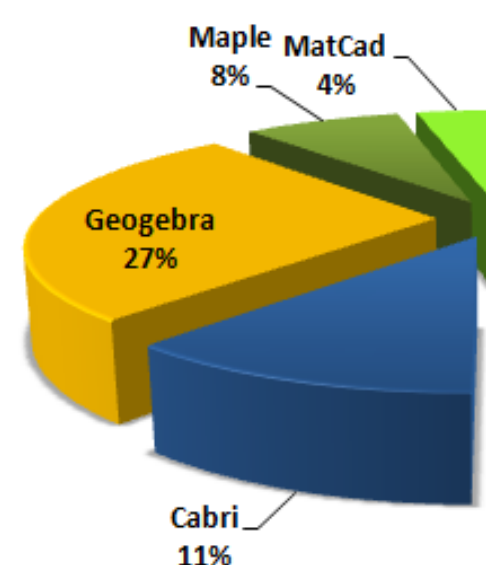

$11 \%$



$4 \%$

Gráfico 04 - Conhecimento de soft wares matemáticos

De tudo isso, constatamos que o professor tem conhecimento de softwares matemáticos, lecionam em escolas dotadas de equipamentos. No entanto, a efetivação do uso desses recursos computacionais como ferramenta didática, na prática pedagógica dos mesmos, não se concretiza. Os fatores preponderantes para isso são a falta de capacitação e a falta de tempo para planejamento de atividades que envolvam aplicação de tais recursos. Isso mais uma vez vem confirmar, conforme os pesquisadores da área vêm tratando dentre eles posso citar, Moran (2008), Sancho (2006), Roulkousky (2011) e Tajra (2008), que para um efetivo uso das novas tecnologias em sala de aula é necessário a formação do professor para utilizá-los.

Diante das respostas dadas pelos professores que participaram da pesquisa, chamamos atenção que existindo na escola recursos computacionais disponíveis, cabe ao professor o interesse e a disposição em utilizá-los. Mas para que isso aconteça também é necessário que o professor tenha condições dignas de trabalho que lhe permita destinar tempo para estudo e aprofundamento sobre o uso das novas tecnologias, em especial softwares matemáticos. Portanto, o uso dos recursos computacionais se torna mais uma tarefa para o professor e o faz sair de sua zona de conforto, algo que nem todos estão dispostos a enfrentar.

\section{Análise e Discussão dos Questionários - Aplicados aos alunos}

Como já dito, duas turmas do Ensino Médio participaram da pesquisa. Uma de 1a série e uma de $3^{a}$ série, que realizaram atividades sobe Função Afim e Quadrática e Equações Polinomiais respectivamente. Com as respostas dadas pelos alunos foi possível obter informações sobre faixa 
etária, conhecimentos de informática, compreensão dos conteúdos estudados, dificuldades e facilidades com o uso do software e as impressões sobre o estudo da matemática usando recursos computacionais.

Os alunos de ambas as séries demonstraram grande interesse em aprender sobre a ferramenta Winplot e tiveram um ótimo desempenho no momento que foram solicitados a usar o software. Uma das questões investigou a compreensão dos conteúdos estudados antes e depois do uso do software. Das respostas dos alunos foi possível concluir que os alunos tiveram um desempenho melhor em compreensão dos conteúdos abordados após o uso do Winplot. Esse dado é confirmado nos gráficos 5 e 6;

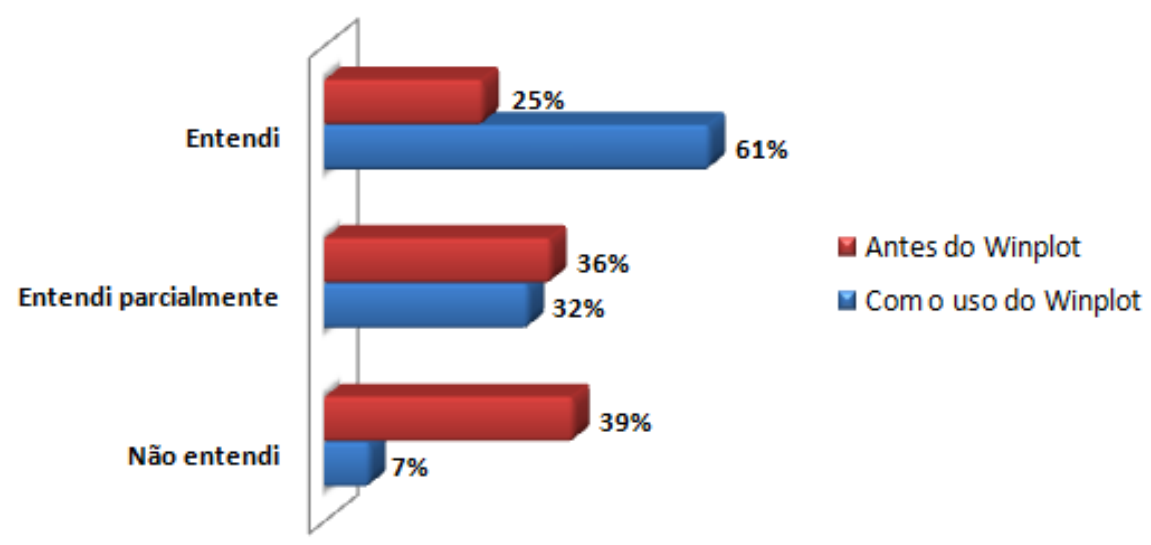

Gráfico 05 - Estudos das Funçôes Afins e Quadráticas

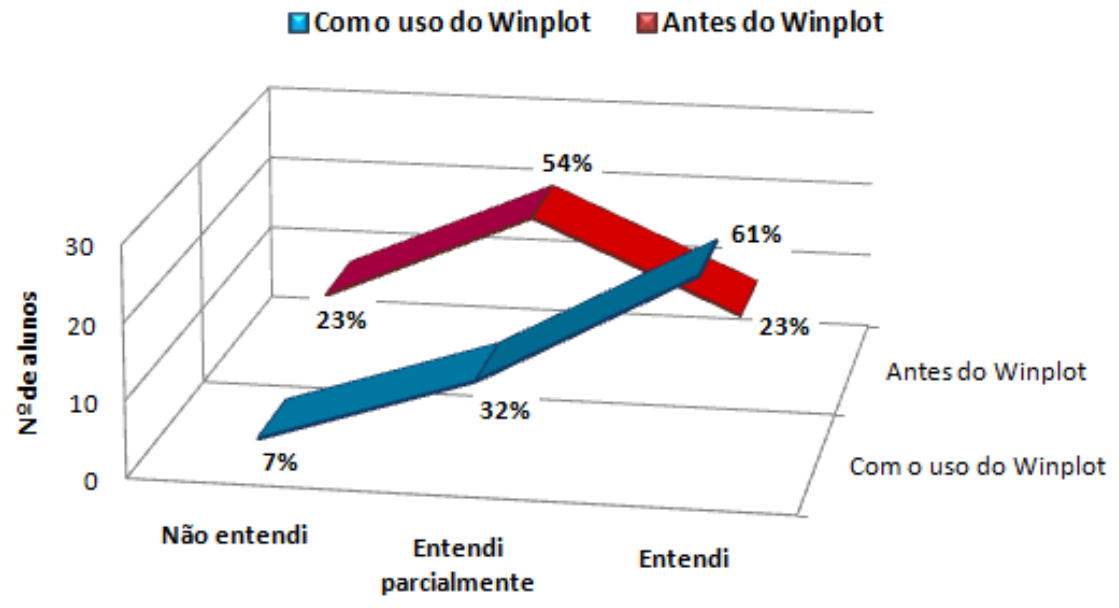

Gráfico 06 - Estudo das Equaçőes Polinomiais

Foi perguntado ao aluno, se sentiu dificuldades quando estudou o conteúdo e como ele avaliou sua dificuldade em compreendê-lo com o auxílio do software.

Verificamos pelas respostas dadas, que a utilização dos recursos computacionais são grandes motivadores, muito provavelmente facilitando a aprendizagem dos conteúdos estudados pelos alunos. De fato, pelas respostas, $61 \%$ afirmaram ter compreendido o conteúdo estudado. 
Número este, bem superior aos $23 \%$ que disseram ter entendido o conteúdo antes de usar o Winplot. Isso já era esperado por nós, uma vez que o software permite a construção do gráfico melhorando a visualização, também é possível identificar as raízes e realizar animações possibilitando a definição de padrões e comportamentos, além de possibilitar a visualização de várias funções num mesmo plano. $\mathrm{O}$ que quando comparado com a aula expositiva e construção com lápis e papel é um grande diferencial.

Assim, analisando essas respostas é possível inferir que o computador contribuiu para uma melhor compreensão do conteúdo, visto que os alunos realizaram a atividade proposta sem grandes dificuldades. Além disso, com o uso do Winplot nos estudos de Funções Polinomiais foi possível explorar gráficos de equações polinomiais de grau maior do que dois o que é quase impossível quando abordado sem o uso de um software. De acordo com Borba e Penteado (2001),

\section{"[...] as mídias informáticas associadas a pedagogias que estejam em ressonância com essas novas tecnologias podem transformar o tipo de matemática que é abordada em sala de aula. (BORBA e PENTEADO, 2001, $p$. 36)"}

Baseado as respostas e na observação da participação dos alunos no transcorrer das atividades deixam evidente que o aluno incorpora muito rapidamente as novas tecnologias e consegue usá-las com uma habilidade notável. Esse fato, por si só, já justificaria a utilização desses recursos nas práticas docentes. Todavia, ressaltamos a importância de que tais atividades sejam bem planejadas e estejam de acordo com o conteúdo sendo explorado. Se bem planejadas resultarão em ações bem sucedidas, redundando numa melhor aprendizagem dos alunos, a qual se constitui o alvo principal na ação docente.

Tanto em relação aos alunos da 1a série quanto aos alunos da 3a série encontramos indicativos consistentes de que o uso dos recursos computacionais pode melhorar sensivelmente o ensino e aprendizagem da matemática. Todavia, vale ressaltar, que tais recursos precisam ser utilizados de forma adequada, planejada e por professores que estejam capacitados para tal. Tal como afirma Tajra (2008),

"O professor precisa conhecer os recursos disponíveis nos programas escolhidos para suas atividades de ensino, somente assim ele estará apto a realizar uma aula dinâmica e segura. Ir para um ambiente de informática sem ter analisado o programa a ser utilizado é o mesmo que ministrar uma aula sem planejamento e sem ideia do que fazer. (p. 107)"

Destacamos ainda, que o uso do software Winplot se mostrou eficaz naquilo que nos propomos que era aliar o uso das tecnologias aos conteúdos matemáticos sendo abordados. Quanto aos alunos, não só conseguiram realizar e entender o que foi proposto, como também o 
fizeram com entusiasmo, interesse e demonstrando bastante habilidade em relação ao uso do software, do computador e seus recursos.

\section{Considerações finais}

Ao término do trabalho de dissertação, ora relatado neste artigo, foi possível perceber que o ensino de matemática auxiliado pelas tecnologias, possibilita bons resultados. Os objetivos foram mostrar a viabilidade do estudo das Funções Afins, Quadráticas e Equações Polinomiais com o uso do software Winplot como ferramenta didática para os alunos da 1a e 3 a série do Ensino Médio, identificar as dificuldades encontradas pelos professores para fazerem uso desses recursos, dentre outros.

Sendo assim, para alcançar esses objetivos foram elaborados questionários, tutoriais e atividades em que os alunos pudessem fazer uso do software, ou seja, para que houvesse uma utilização efetiva dos recursos computacionais como ferramenta pedagógica no ensino da matemática. Com isso, se pretendia responder a algumas questões:

Quais são as maiores dificuldades enfrentadas pelos professores para implementarem ações pedagógicas com o uso de recursos computacionais?

- Os tutoriais e as atividades irão possibilitar ao aluno o melhor uso do Winplot e a compreensão dos conteúdos abordados?

- O uso do software Winplot pode auxiliar o ensino e a aprendizagem no estudo das Funções Afim, Quadrática e Equações Polinomiais?

A análise dos dados me permitiu chegar a algumas conclusões que indicam que os objetivos foram alcançados. Foi possível perceber que as dificuldades dos professores em relação a utilização dos recursos computacionais não são de ordem técnica, como ausência dessas recursos na escola, mas sim pelo fato de a maioria deles não motivação e formação consistente para tal prática. Então, o trabalho apontou para a necessidade de melhor formar os professores para a utilização das novas tecnologias e de melhorar a condição de trabalho dos mesmos. Só assim, podemos esperar um professor estimulado a mudar sua metodologia, planejar atividades diferenciadas, realizá-las em sala de aula, refletir sobre essa utilização. É a constante "promessa" do professor-pesquisador, algo ainda distante das salas de aula atuais. De tudo que abordamos acreditamos que as TIC, em especial os recursos computacionais, ao serem usados pedagogicamente e de maneira planejada, crítica e consciente, podem contribuir de forma indelével na melhoria do ensino de matemática, e por que não dizer da educação em geral. Com isso, formar cidadãos que a sociedade atual exige e espera.

(1) Mestre em Matemática. Programa de Pós-Graduação em Matemática em rede Nacional PROFMAT, UESB. Professor da Educação Básica - SEC - Bahia

88 DOI: Em andamento.

R. Bras. de Ensino de C\&T 
(2) Doutora em Educação - Linha Educação Matemática -UFRN. Professora do Programa de Pós-graduação em Matemática em Rede Nacional - PROFMAT, e do Programa de Pósgraduação em Educação Científica e Formação de Professores, UESB

\section{Referências}

ABU-JAMRA, M. E. B. A matemática e as sua interações com as tecnologias da informação e comunicação. 2005. 182 f. Dissertação (Mestrado em Educação). PUC-PR, Curitiba, 2005.

BETTEGA, M. H. S. Educação continuada na era digital. 2. ed. São Paulo: Cortez, 2010.

BORBA, M. C; PENTEADO, M. G. Informática e Educação Matemática. Belo Horizonte: Autêntica, 2001.

BORGES, A. J. Polinômios do ensino médio: Uma investigação em livros didáticos. 2007. 109 f. Dissertação (Mestrado Profissional em Ensino de Matemática). PUC-SP, São Paulo, 2007.

BRASIL. Ministério da Educação. Secretaria de Educação Média e Tecnológica. Parâmetros Curriculares Nacionais (Ensino Médio). Parte III - Ciências da Natureza, Matemática e suas Tecnologias. Brasília: MEC, 2000.

Parâmetros Curriculares Nacionais + $(\mathbf{P C N}+)$ - Ciências da Natureza e suas Tecnologias. Brasília: MEC, 2002.

CERVO, A. L; BERVAN, P. A; SILVA, R.. Metodologia científica. 6. ed. São Paulo: Pearson Prentice Hall, 2007.

COX, K. K. Informática na educação. 2. ed. Campinas, SP: Autores Associados, 2008.

CRUZ, V. A. G. Metodologia da pesquisa científica. São Paulo: Pearson Pretence Hall, 2010.

FACHIN, O. Fundamentos de metodologia. 5. ed. [rev.] - São Paulo: Saraiva, 2006.

FONSECA, V. G. O uso de tecnologias no ensino médio: A integração do Mathlets no ensino da função afim. 2011. 152 f. Dissertação (Mestrado em Ensino de Matemática). UFRJ/IM, Rio de Janeiro, 2011.

GUIMARÃES, K. P. Desafios e perspectivas para o ensino da matemática. Curitiba: Ibpex, 2010.

KENSKI, V. M. Educação e tecnologias: O novo ritmo da informação. Campinas, SP: Papirus, 2007. . Tecnologias e ensino presencial e a distância. 8. ed. Campinas, SP: Papirus, 2010.

Matemática para Gregos e Troianos. Disponível em:

<http://www.gregosetroianos.mat.br/softwinplot.asp>. Acessado em: jan. de 2013.

MELO, J. M; TOSTA, S. P. Mídia \& Educação. Belo Horizonte: Autêntica Editora, 2008.

DOI: Em andamento. 
MORAN, J. M; MASETTO, M. T.; BEHRENS, M. A. Novas tecnologias e mediações pedagógicas. 8. ed. Campinas, SP: Papirus, 2008.

MOREIRA, M. A. Metodologias de pesquisa em ensino. São Paulo: Editora Livraria da Física, 2011. NOÉ, M. A informática no Ensino da Matemática. Disponível em: <http://www.educador.brasilescola.com/estrategias-ensino/a-informatica-no-ensinomatematica.htm>. Acessado em dez. 2012.

OLIVEIRA, N. Conceito de função: uma abordagem no processo ensino-aprendizagem. 1997. 174 f. Dissertação (Mestrado em Ensino de Matemática). PUC-SP, São Paulo, 1997.

PICCOLI, L A P. A construção de conceitos em matemática: Uma proposta usando tecnologia de informação. 2006. 109 f. Dissertação (Mestrado em Educação em Ciências e Matemática). PUC-RS, Porto Alegre, 2006.

ROULKOUSKY, E. Tecnologias no ensino de matemática. Curitiba: Ibpex, 2011 - Série Matemática em Sala de Aula.

SANCHO, J. M et. al. Tecnologias para transformar a educação. Tradução: Valério Campos. Porto Alegre: Artmed, 2006.

SOFTWARES educacionais. In: Coordenação Reg. de Tecnologia Educacional. Londrina, 2006. Disponível em: <http://www.uel.br/seed/nte/index.html>. Acessado em: 10 de fev. 2013.

SOUSA, J. R. Novo olhar matemática. São Paulo: FTD, 2010. v.1. . v.3.

SOUZA, S. A. Usando o Winplot. Disponível em: <http://www.mat.ufpb.br/sergio/winplot/winplot.html>. Acessado em: jan. 2013.

SUZUKI, J. T. F; RAMPAZZO, S. R.R. Tecnologias em Educação. São Paulo: Pearson Education no Brasil, 2009.

TAJRA, S. F. Informática na Educação: novas ferramentas pedagógicas para o professor na atualidade. 8. ed. rev. ampl. São Paulo: Érica, 2008.

TORNAGHI, A. et al. Tecnologias na escola. Brasília: MEC, 2006. 26p. (Salto para o Futuro). Disponível em: <http://www.unopar.br/bibli01/catalogos.htm>. Acessado em: dez. 2012.

Prof. Silvio Márcio Costa de Jesus

Titulação: Mestre, Programa de Mestrado Profissional em Matemática em Rede Nacional PROFMAT, Campus UESB, 2013

Rede Estadual de Ensino - SEC - Bahia 
Profa. Maria Deusa Ferreira da Silva

Titulação- Dra. Programa de Educação da UFRN, 2010

Professor Adjunto Universidade Estadual do Sudoeste da Bahia- UESB, Departamento de Ciências Exatas e Tecnológicas - DCET

Docente do Programa de Mestrado Profissional em Matemática em Rede Nacional - PROFMAT, UESB e do Programa de Pós-Graduação em Educação Científica e Formação de Professores, PPGECF.

DOI: Em andamento. 